Global Journal of Pure and Applied Mathematics.

ISSN 0973-1768 Volume 13, Number 7 (2017), pp. 3641-3655

(C) Research India Publications

https://dx.doi.org/10.37622/GJPAM/13.7.2017.3641-3655

\title{
Possibility and Probability Aspect to Fuzzy Reliability Analysis of a Network System
}

\author{
$+$ \\ Mukesh K. Sharma \\ Deptt. of Mathematics, \\ R.S.S. (P.G.) College Pilkhuwa, Hapur-245304 (U.P.) India.
}

\begin{abstract}
In the present paper Fuzzy process, similar to a stochastic process is carried out for reliability analysis of the network modeling. Classical reliability analysis carries out the probability and binary state assumption which has been found to be inadequate to handle uncertainties of failure data and modeling. In the present paper we have attempted to review the fuzzy tools when dealing with reliability of series, parallel, bridge, k-out of-n networks systems with concept of probability as well as possibility. In the present paper to overcome this problem, the concept of "fuzzy probability" and fuzzy possibility has been used in to analyze the fuzzy reliability of network.
\end{abstract}

Keywords: Reliability, probability, possibility, fuzzy sets, series, parallel, bridge and k-out of n-Systems.

\section{INTRODUCTION}

The conventional reliability of a system is defined as the probability that the system performs its assigned function properly during a predefined period under the condition that system behavior can be fully characterized in the context of probability measure. However, in the real world problems, the system parameters are often fuzzy/ imprecise because of incomplete or non-obtainable information, and the probabilistic approach to the conventional reliability analysis is inadequate to account for such built-in uncertainties in the system. For this purpose, the concept of fuzzy reliability has been introduced and formulated in the context of possibility theory. Processes, components, equipments, systems, and people are not perfect and not free from failures. In a naïve, simplistic, and deterministic view, we can have perfection with perfect reliability. In the real world we fall short of perfection. Everything fails either 
because of events or from aging deteriorations. Reliability engineering is a strategic task concerned with predicting and avoiding failures. For quantifying reliability issues it is important to know why, how, how often the failures occur and what is the cost of failure in terms of money, time and goodwill. Reliability issues are bound to the physics of failure mechanisms so the failure mechanisms can be mitigated. In fact almost all potential failures are seldom well known or well understood, that makes failure prediction a probabilistic issue for reliability analysis. Taking into consideration the role of failure engineering in system reliability estimation, we intend to study in this paper, various network configurations in fuzzy approach. Reliability analysis of a network is known since the early stages of the standard reliability theory based on probabilistic modeling. Pursuing the theme of the work, we shall now replace probabilistic modeling by possibilistic models using the concept of fuzzy probability. This paper deals with probist and profust reliability estimates of various network configurations.

Present paper basically includes explaining how fuzzy set concepts can be applied in system reliability evaluation of a series, parallel, bridge, k-out of $-\mathrm{n}$ network and nonseries parallel network, particularly in a situation where the data are inadequate or unreliable. Reliability of elements in a network depends on numerous factors. To evaluate reliability associated with considering all such factors would become very difficult. The fuzzy modeling has been applied for subjective evaluation, which replaces the analytic approach. The basic operations on fuzzy sets can be represented by simple networks as in the theory of reliability networks.

\section{OPERATIONS ON FUZZY NUMBERS THROUGH $\alpha$-CUTS}

Generally a fuzzy interval is represented by two end points $\mathrm{a}_{1}$ and $\mathrm{a}_{3}$ and a peak point $\mathrm{a}_{2}$ as $\left[\mathrm{a}_{1}, \mathrm{a}_{2}, \mathrm{a}_{3}\right]$.

For $\alpha \in[0,1]$, the $\alpha$-cut set $\mathrm{A}_{\alpha}$ of fuzzy number $\mathrm{A}$ is an interval given by,

$$
A_{\alpha}=\left[a_{\ell}^{(\alpha)}, a_{r}^{(\alpha)}\right] ; a_{\ell}^{(\alpha)} \leq a_{r}^{(\alpha)}
$$

Let $\mathrm{A}_{\alpha}=\left\lfloor\mathrm{a}_{\ell}^{(\alpha)}, \mathrm{a}_{\mathrm{r}}^{(\alpha)}\right\rfloor \quad$ and $\quad \mathrm{B}_{\alpha}=\left\lfloor\mathrm{b}_{\ell}^{(\alpha)}, \mathrm{b}_{\mathrm{r}}^{(\alpha)}\right\rfloor$

operations of addition, subtractions, multiplication and division between the two $\alpha$ cut sets are defined as following:

(i) Addition:

$$
(\mathrm{A}+\mathrm{B})_{\alpha}=\left\lfloor\mathrm{a}_{\ell}^{(\alpha)}+\mathrm{b}_{\ell}^{(\alpha)}, \mathrm{a}_{\mathrm{r}}^{(\alpha)}+\mathrm{b}_{\mathrm{r}}^{(\alpha)}\right\rfloor
$$

(ii) Subtractions:

$$
(A-B)_{\alpha}=\left[a_{\ell}^{(\alpha)}-b_{r}^{(\alpha)}, a_{r}^{(\alpha)}-b_{\ell}^{(\alpha)}\right]
$$


Possibility and Probability Aspect to Fuzzy Reliability Analysis of a Network System 3643

(iii) Multiplication:

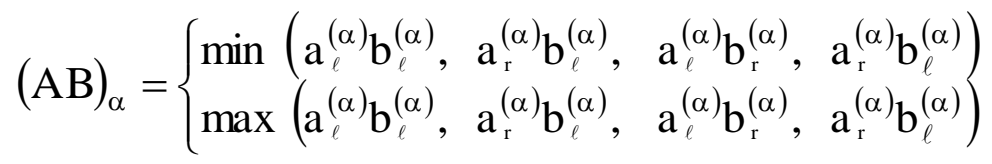

(iv) Division:

$$
\begin{aligned}
& (\mathrm{A} / \mathrm{B})_{\alpha}=\left[\mathrm{a}_{\ell}^{(\alpha)}, \mathrm{a}_{\mathrm{r}}^{(\alpha)}\right] \cdot\left[1 / \mathrm{b}_{\mathrm{r}}^{(\alpha)}, 1 / \mathrm{b}_{\ell}^{(\alpha)}\right] \\
& \text { if } 0 \notin\left[\mathrm{b}_{\ell}^{(\alpha)}, \mathrm{b}_{\mathrm{r}}^{(\alpha)}\right]
\end{aligned}
$$

We shall use only triangular and trapezoidal fuzzy numbers to evaluate fuzzy reliabilities of various networks. The $\alpha$-cut sets for these fuzzy numbers can be expressed in the following manner:

(A) $\alpha$-Cut set $A_{\alpha}$ for triangular fuzzy number: -

Let $A=\left[a_{1}, a_{2}, a_{3}\right]$ be a triangular fuzzy number whose membership function is

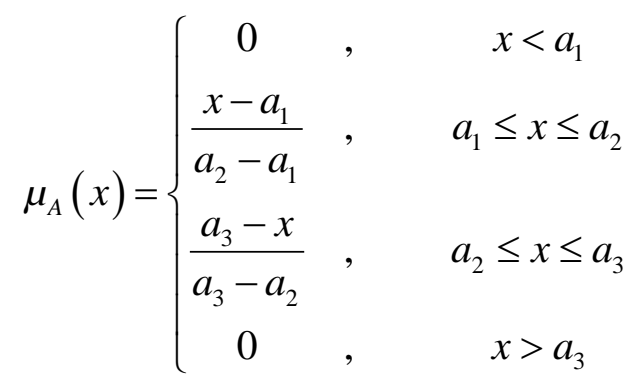

By $\alpha$-cut operation, $\mathrm{A}_{\alpha}$ shall be obtained as follows $\forall \alpha \in[0,1]$

$$
\frac{a_{1}^{(\alpha)}-a_{1}}{a_{2}-a_{1}}=\alpha \text { and } \frac{a_{3}-a_{3}^{(\alpha)}}{a_{3}-a_{2}}=\alpha
$$

therefore, we get

$\mathrm{a}_{1}^{(\alpha)}=\left(\mathrm{a}_{2}-\mathrm{a}_{1}\right) \alpha+\mathrm{a}_{1}$

$a_{3}^{(\alpha)}=-\left(a_{3}-a_{2}\right) \alpha+a_{3}$

thus $\mathrm{A}_{\alpha}=\left\lfloor\mathrm{a}_{1}^{(\alpha)}, \mathrm{a}_{3}^{(\alpha)}\right\rfloor$

$$
=\left[\left(a_{2}-a_{1}\right) \alpha+a_{1},-\left(a_{3}-a_{2}\right) \alpha+a_{3}\right]
$$

(B) $\alpha$-Cut set $A_{\alpha}$ for Trapezoidal fuzzy number: Trapezoidal fuzzy number is defined as follows:

$$
A=\left[a_{1}, a_{2}, a_{3}, a_{4}\right]
$$


The membership function of this fuzzy number will be defined as:

$\mu_{A}(x)=\left\{\begin{array}{ccc}0 & , & x<a_{1} \\ \frac{x-a_{1}}{a_{2}-a_{1}} & , & a_{1} \leq x \leq a_{2} \\ 1 & , & a_{2} \leq x \leq a_{3} \\ \frac{a_{4}-x_{1}}{a_{4}-a_{3}} & , & a_{3} \leq x \leq a_{4} \\ 0 & , & x>a_{4}\end{array}\right.$

$\alpha$-cut interval for this shape is $\forall \alpha \in[0,1]$

$A_{\alpha}=\left[\left(a_{2}-a_{1}\right) \alpha+a_{1},-\left(a_{4}-a_{3}\right) \alpha+a_{4}\right]$

When $\mathrm{a}_{2}=\mathrm{a}_{3}$, the trapezoidal fuzzy number will coincide with triangular fuzzy number.

\section{NOTATIONS}

$P_{i}=$ Fuzzy probability of an event

$P_{\bar{i}}=$ Complementation of a fuzzy probability $P_{i}$

$\mu_{p_{i}}(p)=$ Membership function of fuzzy probability $\mathrm{P}_{\mathrm{i}}$

$P_{i j}=$ Multiplication of two fuzzy probabilities $P_{i}$ and $P_{j}$ i.e. $P_{i j}=P_{i} . P_{j}$

$P_{i \bar{j}}=$ Complementation of a fuzzy probability $P_{i j}$ i.e. $\overline{P_{i} \cdot P_{j}}$

$R_{s}=\quad$ Fuzzy reliability of a system

$\prod_{x_{k}}=$ possibilistic reliability

$\tilde{\widetilde{J}}=$ possibility distribution

\section{DEFUZZIFICATION}

A defuzzification is a process to get a non-fuzzy control action that best presents the possibility distribution of an inferred fuzzy control action. Out of the three commonly used defuzzification strategies used that is, Mean of Maximum, Centre of gravity of area and Bisector of Area. We have taken Bisector of Area (BOA) as a defuzzification method, which is described as follows: 
As shown in the figure the BOA generates the action $\left(Z_{0}\right)$ which partitions the area into two regions of equal area.

$$
\begin{gathered}
\text { If } \mathrm{W}=\operatorname{Support}(\mathrm{C}) \text {, } \\
\alpha=\min \{z \mid z \in W\} \quad \text { and } \beta=\max \{z \mid z \in W\} \text { then action } z_{0} \text { is given by } \\
\qquad \int_{\alpha}^{Z_{0}} \mu_{C}(Z) d z=\int_{Z_{0}}^{\beta} \mu_{C}(Z) d z \ldots \ldots \ldots \ldots \ldots \ldots \ldots \ldots \ldots \text { (3) }
\end{gathered}
$$

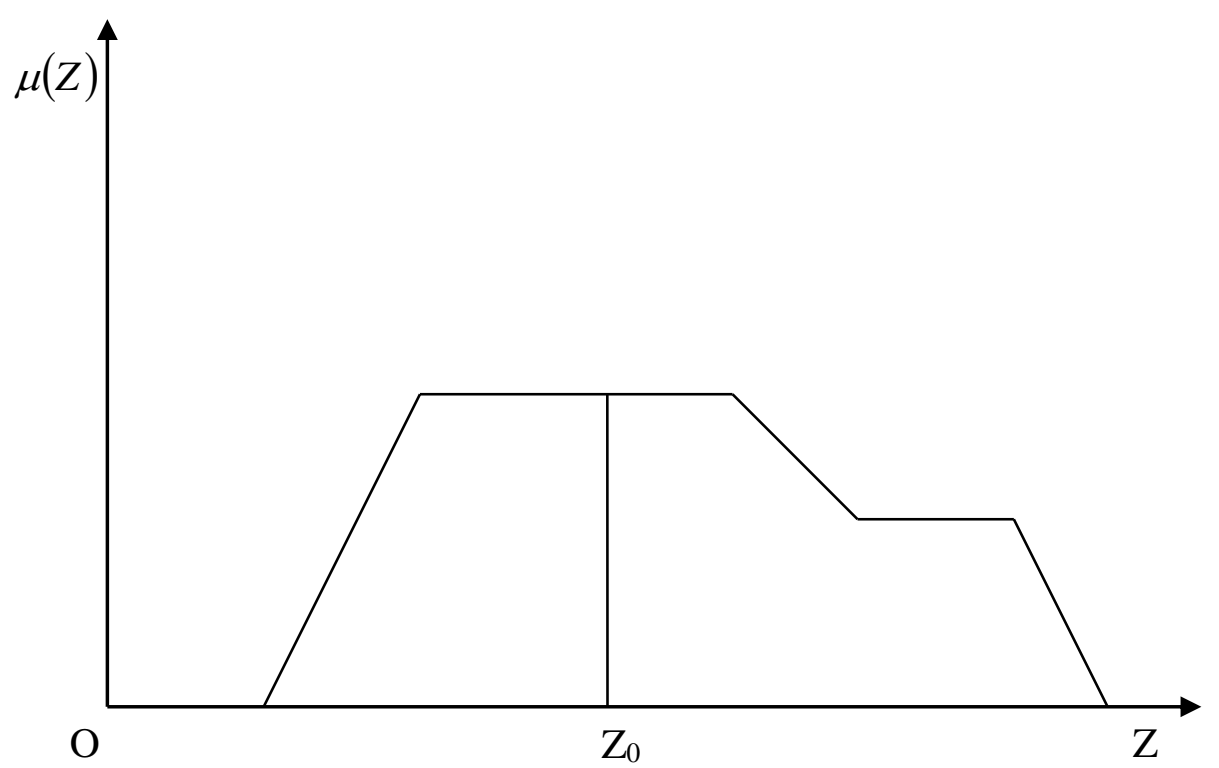

Fig-1

\section{PROFUST RELIABILITY OF THE NETWORKS:}

\section{(a) Using fuzzy numbers: -}

Reliability of a probist system is a crisp number. Suppose a probist system comprises $n$ components whose reliabilities are $R_{1}, R_{2}----, R_{n}$ respectively, then the system reliability $\mathrm{R}$ is precisely determined by,

$$
\mathrm{R}=\mathrm{G}\left(\mathrm{R}_{1}, \mathrm{R}_{2},----\mathrm{R}_{\mathrm{n}}\right)
$$

where $\mathrm{R}_{1}, \mathrm{R}_{2}----, \mathrm{R}_{\mathrm{n}} \in\left[\begin{array}{ll}0,1 & 1\end{array}\right]$ and $G:\left[\begin{array}{ll}0 & 1\end{array}\right]^{n} \rightarrow\left[\begin{array}{ll}0 & 1\end{array}\right]$

\section{For a Series System:-}

It is known that the reliability $\mathrm{R}$ of a probist series system of $\mathrm{n}$-components is

$$
\mathrm{R}=\prod_{i=1}^{n} R_{i}
$$


To obtain the profust reliability we consider $\mathrm{R}_{1}, \mathrm{R}_{2}----, \mathrm{R}_{\mathrm{n}}$ to be triangular fuzzy numbers,

Therefore, $\quad R_{i}=\left(a_{i_{1}}, a_{i_{2}}, a_{i_{3}}\right) ; \quad i=1,2,----, n$

Then from $\alpha$-cut operations on fuzzy number, this can be written as,

$$
\left(R_{i}\right)_{\alpha}=\left[\left(a_{i_{2}}-a_{i_{1}}\right) \alpha+a_{i_{1}},-\left(a_{i_{3}}-a_{i_{2}}\right) \alpha+a_{i_{3}}\right] ; \forall \alpha \in[0,1]
$$

Therefore, the profust reliability $\left(R_{s}\right)$ expression is given by,

$$
\begin{aligned}
R_{s} & =\prod_{i=1}^{n}\left(R_{i}\right)_{\alpha} \\
& =\left[\prod_{i=1}^{n}\left\{\left(a_{i_{2}}-a_{i_{1}}\right) \alpha+a_{i_{1}}\right\}, \prod_{i=1}^{n}\left\{-\left(a_{i_{3}}-a_{i_{2}}\right) \alpha+a_{i_{3}}\right\}\right] \quad \forall \alpha \in[0,1]
\end{aligned}
$$

\section{For a parallel system:-}

Let us consider a probist parallel system of order n, i.e.

$$
R_{p}=1-\prod_{i=1}^{n}\left(1-R_{i}\right)
$$

Suppose, $\mathrm{R}_{1}, \mathrm{R}_{2}----, \mathrm{R}_{\mathrm{n}}$ are triangular fuzzy numbers, then so are $1-\mathrm{R}_{1}---, 1-\mathrm{R}_{\mathrm{n}}$

This will give us that $\mathrm{R}$ is a triangular fuzzy number,

$$
\begin{aligned}
R_{i} & =\left(a_{i_{1}}, a_{i_{2}}, a_{i_{3}}\right) ; i=1,2,----, n \\
& =[1,1]-\prod_{i=1}^{n}\left[\left(a_{i_{3}}-a_{i_{2}}\right) \alpha+1-a_{i_{3}},-\left(a_{i_{2}}-a_{i_{1}}\right) \alpha+1-a_{i_{1}}\right] \\
& =
\end{aligned}
$$

or, if we consider,

$R_{i}=\left(m_{i}-\alpha_{i}, m_{i}, m_{i}+\beta_{i}\right) ; i=1,2,----, n$

Then,

$$
R=1-\prod_{i=1}^{n}\left(1-R_{i}\right)
$$


Possibility and Probability Aspect to Fuzzy Reliability Analysis of a Network System 3647

$$
\begin{aligned}
& =1-\prod_{i=1}^{n}\left(1-\left(m_{i}-\alpha_{i}, m_{i}, m_{i}+\beta_{i}\right)\right) \\
& =1-\prod_{i=1}^{n}\left(1-\left(m_{i}+\beta_{i}\right), 1-m_{i}, 1-\left(m_{i}-\alpha_{i}\right)\right) \\
& =1-\left(\prod_{i=1}^{n}\left[1-\left(m_{i}+\beta_{i}\right)\right], \prod_{i=1}^{n}\left(1-m_{i}\right), \prod_{i=1}^{n}\left[1-\left(m_{i}-\alpha_{i}\right)\right]\right) \\
& \quad=\left(1-\prod_{i=1}^{n}\left[1-\left(m_{i}-\alpha_{i}\right)\right], 1-\prod_{i=1}^{n}\left(1-m_{i}\right), 1-\prod_{i=1}^{n}\left[1-\left(m_{i}+\beta_{i}\right)\right]\right)
\end{aligned}
$$

Suppose, $\mathrm{R}_{1}, \mathrm{R}_{2}----, \mathrm{R}_{\mathrm{n}}$ are trapezoidal fuzzy numbers, then $1-\mathrm{R}_{1}, 1-\mathrm{R}_{2}----, 1-\mathrm{R}_{\mathrm{n}}$ are also trapezoidal fuzzy numbers, $R_{i}=\left(a_{i_{1}}, a_{i_{2}}, a_{i_{3}}, a_{i_{4}}\right) ; i=1,2,----, n$

Then,

$$
\begin{aligned}
& 1-R_{i}=\left(1-a_{i_{4}}, 1-a_{i_{3}}, 1-a_{i_{2}}, 1-a_{i_{1}}\right) ; i=1,2,---n \\
& \prod_{i=1}^{n}\left(1-R_{i}\right)=\left(\prod_{i=1}^{n}\left(1-a_{i_{4}}\right), \prod_{i=1}^{n}\left(1-a_{i_{3}}\right), \prod_{i=1}^{n}\left(1-a_{i_{2}}\right), \prod_{i=1}^{n}\left(1-a_{i_{1}}\right)\right) \\
& R \approx\left(1-\prod_{i=1}^{n}\left(1-a_{i_{1}}\right), 1-\prod_{i=1}^{n}\left(1-a_{i_{2}}\right), 1-\prod_{i=1}^{n}\left(1-a_{i_{3}}\right), 1-\prod_{i=1}^{n}\left(1-a_{i_{4}}\right)\right)
\end{aligned}
$$

\section{(b) Using Extension principle:-}

\section{k-out of n-systems:-}

The structure of the $\mathrm{i}^{\text {th }}$ component is described by a binary variable $\mathrm{X}_{\mathrm{i}}$, where,

$$
X_{i}=\left[\begin{array}{ll}
1 & ; \text { if } i^{\text {th }} \text { component is functioning } \\
0 & \text {;if } i^{\text {th }} \text { component is failed }
\end{array}\right.
$$

For $\mathrm{i}=1,2, \ldots \ldots \ldots \ldots \ldots \ldots \mathrm{n}$ is the number of component in the system.

$\mathrm{X}=\left(\mathrm{x}_{1}, \mathrm{X}_{2}, \ldots \ldots \ldots . ., \mathrm{X}_{\mathrm{n}}\right)$ is known as the state vector. Furthermore, we assume that by knowing the states of all the n-components, we also know whether the system is functioning or not.

So we can write

$$
\phi=\phi(x) \text { where } \mathrm{X}=\left(\mathrm{x}_{1}, \mathrm{X}_{2}, \ldots \ldots \ldots, \mathrm{X}_{\mathrm{n}}\right)
$$

and $\phi(x)$ is called the structure function of the system. 
In the reliability sense we consider a system of $\mathrm{n}$ components with fuzzy reliabilities $\tilde{r}_{1}, \tilde{r}_{2}, \ldots \ldots \ldots \ldots \ldots . . . . . \tilde{r}_{n}$ and assuming statistical independent with each other, and then the reliability of the total system $\tilde{R}$ is given by,

$$
\tilde{R}=\phi\left(\tilde{r}_{1}, \tilde{r}_{2}, \ldots \ldots \ldots \ldots \ldots . . \tilde{r}_{n}\right)
$$

where each $\tilde{r}_{i}$ may have a different type of membership functions. We now derive the reliability of a general fuzzy k-out-of-n system.

The structure function is given by,

$$
\phi\left(\tilde{r}_{1}, \tilde{r}_{2}, \ldots \ldots \ldots \ldots \ldots \ldots . . \tilde{r}_{n}\right)=\sum_{i=k}^{n}\left(\begin{array}{l}
n \\
k
\end{array}\right) \tilde{r}_{i}^{k}\left(1-\tilde{r}_{i}\right)^{n-k}
$$

The reliability for a fuzzy k-out- of-n system is;

$\phi_{\alpha}^{L}=\min \sum_{i=k}^{n}\left(\begin{array}{l}n \\ k\end{array}\right) x_{i}^{k}\left(1-x_{i}\right)^{n-k} \quad$ And $\quad \phi_{\alpha}^{R}=\max \sum_{i=k}^{n}\left(\begin{array}{l}n \\ k\end{array}\right) x_{i}^{k}\left(1-x_{i}\right)^{n-k}$

\section{BRIDGE NETWORK}

In this section of the paper we demonstrate that the reliability of a non series- parallel network i.e. bridge network, can be calculated with the use of two fuzzy arithmetic operations i.e. multiplication and complementation. It would be proper to discuss in brief the concept of structure functions including minimal paths and minimal cuts before we take up the case of bridge network.

\section{Structure functions: -}

We shall also make an assumption which is central in classical, two-state reliability theory that there exists a mapping $\phi: L^{n} \rightarrow L$ i.e. $\phi:\left[\begin{array}{ll}0 & 1\end{array}\right]^{n} \rightarrow\left[\begin{array}{ll}0 & 1\end{array}\right]$, which maps the states of the components to the corresponding state of the system:

$$
\mathrm{Xs}=\phi\left(\mathrm{x}_{1} \ldots \mathrm{x}_{\mathrm{n}}\right) .
$$

$\phi$ is called the two-valued structure function of the system S. It is furthermore assumed that such a two-valued structure function $\phi$ is isotonic - if the components work better, the system as a whole cannot do worse - , that $\phi$ (fail . . . f fail) $=$ fail - if all the components fail then the system fails - and that $\phi$ (work $\ldots$. work $)=$ work if all the components work, the system works. 


\section{Minimal paths and minimal cuts: -}

Let $(\mathrm{L}, \leq)$ be a bounded poset with top $1_{\mathrm{L}}$ and bottom $0_{\mathrm{L}}$. Let $\mathrm{A} \subseteq\{1 \ldots \mathrm{n}\}$ be a set of components of the structure function $\phi$. Then we define the element $\mathrm{p}_{(\mathrm{L}, \leq)}(\mathrm{A})$ $=\left(\beta_{1}, \beta_{2}, \ldots \ldots . . \beta_{n}\right)$ of $\mathrm{L}^{\mathrm{n}}$ as follows:

$$
(\forall \mathrm{k} \in\{1 \ldots \mathrm{n}\})\left(\beta_{k}=1_{\mathrm{L}} \Leftrightarrow \mathrm{k} \in \mathrm{A} \text { and } \beta_{k}=0_{\mathrm{L}} \Leftrightarrow \mathrm{k} \phi \mathrm{A}\right) .
$$

A set of components $A \subseteq\{1 \ldots \mathrm{n}\}$ is called a path (set) of the two-valued structure function $\phi$ iff $\phi \cdot \mathrm{p}_{(\mathrm{L}, \leq)}(\mathrm{A})=$ work. In other words, a path is a set of components such that if these components work, the system works. Dually, a set of components $\mathrm{B} \subseteq\{1 \ldots \mathrm{n}\}$ is called a cut (set) of $\phi$ iff $\phi \cdot \mathrm{p}_{(\mathrm{L}, \leq)}(\mathrm{coB})=$ fail. In other words, a cut is a set of components such that if these components fail, the system fails.

A minimal set of components, such that if these components fail, the system $\mathrm{S}$ fails, is called a minimal cut (set) of the system S. Dually, a minimal set of components, such that if these components work, the system $S$ works, is called a minimal path (set) of the system $\mathrm{S}$.

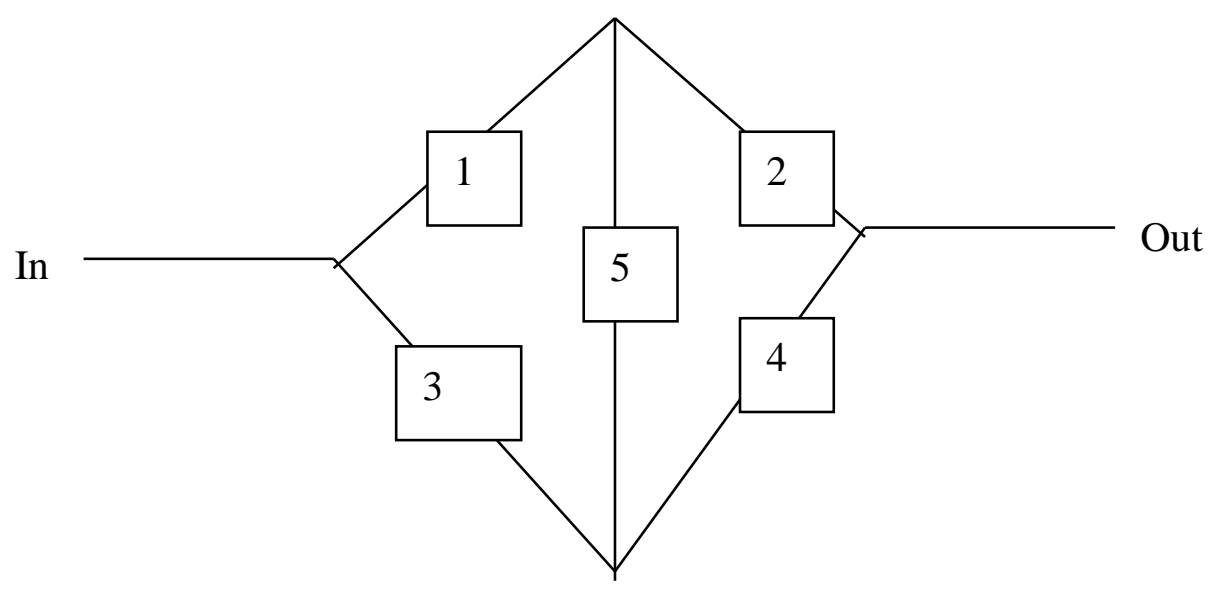

Fig-2

\section{A Bridge Network}

(Non-Series Parallel Network)

(i) Multiplication of fuzzy sets

(ii) Complementation of fuzzy sets

Let $S_{m} \equiv m^{\text {th }}$ minimal path set and $P_{m}$ be the fuzzy probability associated with $S_{m}$.

Let $\mathrm{R}_{\mathrm{m}}=$ fuzzy reliability at the mth step of the sum of fuzzy path probabilities. Then reliability expression can be formulated as, 
$\mathrm{R}_{\mathrm{m}}=\mathrm{R}_{\mathrm{m}-1}+$ probability $\left\{S_{m} \cap \overline{\left(\bigcup_{i=1}^{m-1} S_{i}\right)}\right\}$

$\mathrm{R}_{\mathrm{m}}=\mathrm{R}_{\mathrm{m}-1}+$ probability $\left\{S_{m} \cap \overline{S_{1}} \cap \overline{S_{2}}----\cap \overline{S_{m-1}}\right\}$

We now evaluate the fuzzy reliability of the bridge network given in the figure.

There are four minimum path sets in a bridge network:

$(1,2),(3,4),(1,5,4)$, and $(3,5,2)$

These paths can be shown by the following figure:

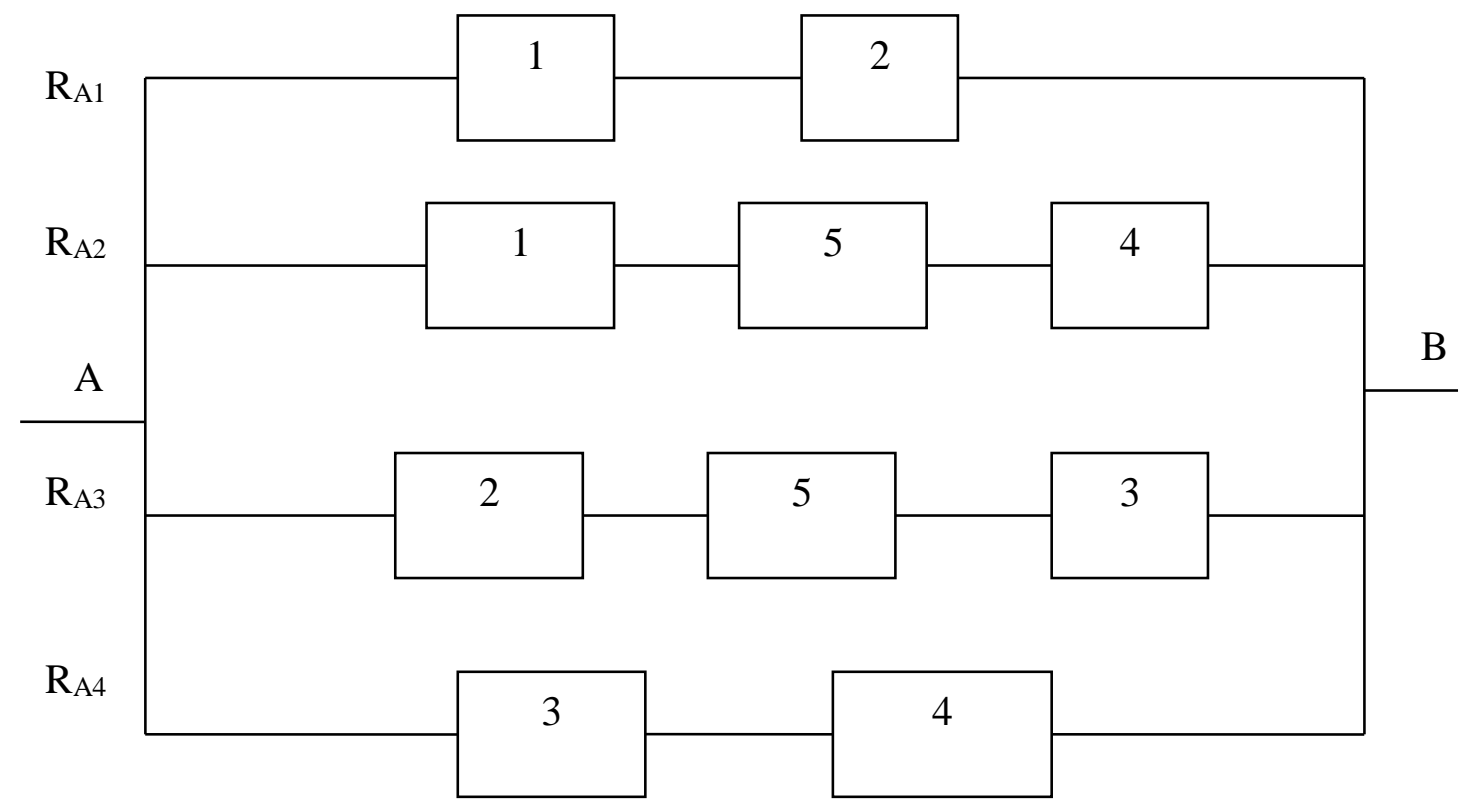

Fig-3

Let,

$$
\begin{aligned}
& S_{1}=1 \bigcap 2 \text { and } P_{r}\left(S_{1}\right) \equiv P_{12}=P_{1} \cdot P_{2}, \\
& S_{2}=3 \bigcap 4 \text { and } P_{r}\left(S_{2}\right) \equiv P_{34}=P_{3} \cdot P_{4}, \\
& S_{3}=1 \bigcap 4 \bigcap 5 \text { and } P_{r}\left(S_{3}\right) \equiv P_{145}=P_{1} \cdot P_{4} \cdot P_{5}, \\
& S_{4}=2 \bigcap 3 \bigcap 5 \text { and } P_{r}\left(S_{4}\right) \equiv P_{235}=P_{2} \cdot P_{3} \cdot P_{5}
\end{aligned}
$$

Now to obtain reliability of the bridge network, we first calculate the reliabilities of each path.

Let $R_{A_{1}}, R_{A_{2}}, R_{A_{3}}$ and $R_{A_{4}}$ denote the reliabilities of $\mathrm{S}_{1}, \mathrm{~S}_{2}, \mathrm{~S}_{3}$ and $\mathrm{S}_{4}$ respectively. These can be evaluated as 
Possibility and Probability Aspect to Fuzzy Reliability Analysis of a Network System 3651

$$
\begin{aligned}
& R_{A_{1}} \equiv P_{1} \cdot P_{2} \\
& R_{A_{2}} \equiv P_{\overline{12}} P_{3} \cdot P_{4} \\
& R_{A_{3}} \equiv P_{\overline{12}} \cdot P_{\overline{34}} \cdot P_{1} \cdot P_{4} \cdot P_{5} \\
& R_{A_{4}} \equiv P_{\overline{12}} \cdot P_{\overline{34}} \cdot P_{\overline{145}} \cdot P_{2} \cdot P_{3} \cdot P_{5}
\end{aligned}
$$

Expressing the system reliability in terms of probability, the system fuzzy reliability as;

$$
\tilde{R}_{s}=1-\left(R_{\bar{A}_{1}} \cdot R_{\bar{A}_{2}} \cdot R_{\bar{A}_{3}} \cdot R_{\bar{A}_{4}}\right)
$$

Now let us assume that the trapezoidal membership function for elements 1,2,3,4 and 5 of bridge network is given by the following expression:

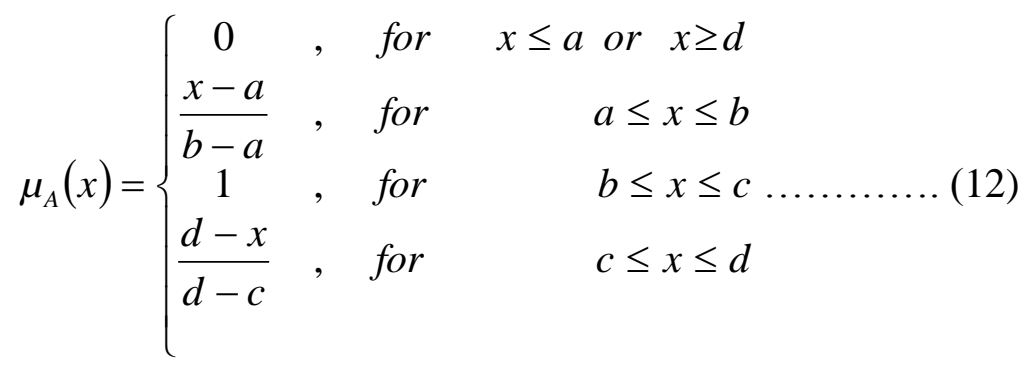

$$
\begin{aligned}
& =(\mathrm{a}, \mathrm{b}, \mathrm{c}, \mathrm{d})
\end{aligned}
$$

For numerical computation, we consider the following trapezoidal fuzzy numbers

$$
\begin{aligned}
& \mu_{P_{1}}(x)=\{0.25,0.92,0.96,0.98\}=\left\{\begin{array}{cc}
0 & \text { if } x \leq 0.25, x \geq 0.98 \\
\frac{x-.25}{.67} & \text { if } .25 \leq x \leq .92 \\
1 & \text { if } .92 \leq x \leq .96 \\
\frac{.98-x}{.02} & \text { if } .96 \leq x \leq .98
\end{array}\right. \\
& \mu_{P_{2}}(x)=\{0.35,0.89,0.93,0.97\}=\left\{\begin{array}{ccc}
0 & \text { if } \quad x \leq 0.35, x \geq 0.97 \\
\frac{x-.35}{.54} & \text { if } .35 \leq x \leq .89 \\
1 & \text { if } & .89 \leq x \leq .93 \\
\frac{.97-x}{.04} & \text { if } & .93 \leq x \leq .97
\end{array}\right.
\end{aligned}
$$




$$
\begin{aligned}
& \mu_{P_{3}}(x)=\{0.45,0.69,0.79,0.91\}=\left\{\begin{array}{ccc}
0 & \text { if } & x \leq 0.45, x \geq 0.91 \\
\frac{x-.45}{.24} & \text { if } & .45 \leq x \leq .69 \\
1 & \text { if } & .69 \leq x \leq .79 \\
\frac{.91-x}{.12} & \text { if } & .79 \leq x \leq .91
\end{array}\right. \\
& \mu_{P_{4}}(x)=\{0.21,0.47,0.65,0.75\}=\left\{\begin{array}{ccc}
\frac{x-.21}{.26} & \text { if } & .21 \leq x \leq .47 \\
1 & \text { if } & .47 \leq x \leq .65 \\
\frac{.75-x}{.10} & \text { if } & .65 \leq x \leq .75
\end{array}\right. \\
& \mu_{P_{5}}(x)=\{0.16,0.32,0.46,0.68\}=\left\{\begin{array}{ccc}
0 & \text { if } & x \leq 0.16, x \geq 0.68 \\
\frac{x-.16}{.16} & \text { if } & .16 \leq x \leq .32 \\
1 & \text { if } & .32 \leq x \leq .46 \\
\frac{.68-x}{.22} & \text { if } & .46 \leq x \leq .68
\end{array}\right.
\end{aligned}
$$

Now from these fuzzy probabilities we will calculate the fuzzy reliability by using the fuzzy multiplication and fuzzy complementation. The fuzzy reliability of all the paths can be obtained by as

$$
\left(R_{\bar{A}_{1}} \cdot R_{\bar{A}_{2}} \cdot R_{\bar{A}_{3}} \cdot R_{\bar{A}_{4}}\right)=\{0.08,0.78,0.85,0.97\}
$$

The fuzzy reliability of the whole system can be obtained by using the equation (7) as,

$$
\begin{aligned}
\tilde{R}_{s} & =1-(0.08 * 0.78 * 0.85 * 0.97) \\
& =0.948851 \ldots \ldots \ldots \ldots \ldots \ldots \ldots \ldots
\end{aligned}
$$

\section{POSFUST RELIABILITY OF A BRIDGE NETWORK}

Consider a system with 5 components, whose graphical representation is given in fig. 4 From the minimal path set and the minimal cut set theory we see that the given system of 5 components has 4 minimal path set and 5 minimal cut set. i.e.

We have $n=$ no. of components $=5$ and

Minimal path set $\mathrm{n}_{\mathrm{p}}=4$ and the minimal path sets are given by $P_{1}=\{1,4\}$, $P_{2}=\{2,5\}, P_{3}=\{1,3,5\}, P_{4}=\{2,3,4\}$ 
minimal cut set $\mathrm{n}_{\mathrm{c}}=4$.

and the minimal cut sets are given by $C_{1}=\{1,2\}, C_{2}=\{4,5\}, C_{3}=\{1,3,5\}$, $C_{4}=\{2,3,4\}$

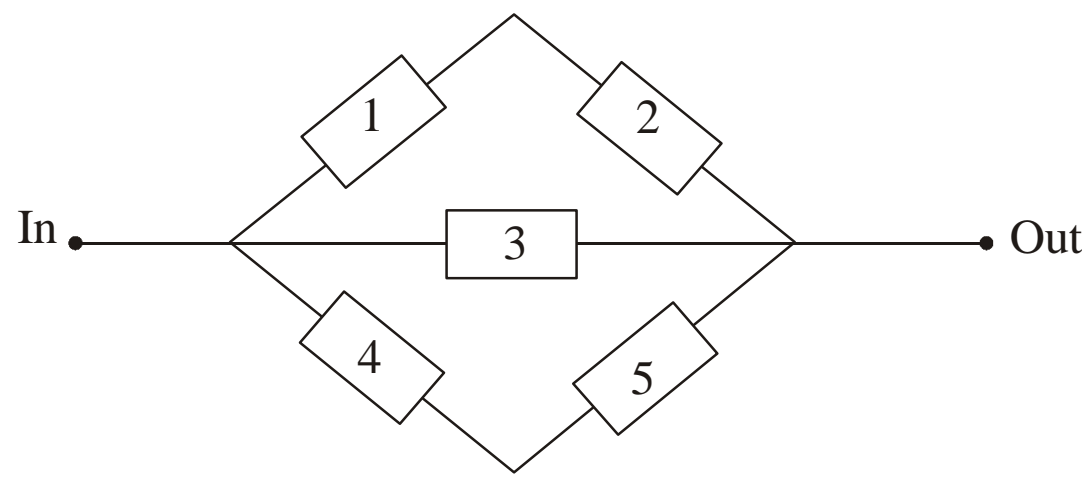

Fig-4

for every two valued function $\phi$, there exists structure function in minimal path sets and cut sets respectively, such that for nay $\left(\mathrm{v}_{1}, \mathrm{v}_{2}, \mathrm{v}_{3}\right.$, $\left.\mathrm{v}_{\mathrm{n}}\right)$ in $\mathfrak{J}^{n}$

We have,

$\phi\left(v_{1}, v_{2}, \ldots \ldots \ldots v_{n}\right)=\underset{1 \leq r \leq n_{p}}{\vee} \underset{i \in p_{r}}{\wedge} v_{i}=$ path set and

$\phi\left(v_{1}, v_{2}, \ldots \ldots \ldots v_{n}\right)=\underset{1 \leq r \leq n_{p}}{\wedge} \underset{i \in c}{\vee} v_{i}=$ cut set

Now the structure function for the minimal path set can be written as

$\phi\left(v_{1}, v_{2}, v_{3}, v_{4}, v_{5}\right)=\left(v_{1} \wedge v_{4}\right) \vee\left(v_{2} \wedge v_{5}\right) \vee\left(v_{1} \wedge v_{3} \wedge v_{5}\right) \vee\left(v_{2} \wedge v_{3} \wedge v_{4}\right)$

and the minimal cut set is given by

$\phi\left(v_{1}, v_{2}, v_{3}, v_{4}, v_{5}\right)=\left(v_{1} \vee v_{2}\right) \wedge\left(v_{4} \vee v_{5}\right) \wedge\left(v_{1} \vee v_{3} \vee v_{5}\right) \wedge\left(v_{2} \vee v_{3} \vee v_{4}\right)$

Now let we consider that $r_{i}$ be the possibilistic reliability of component $C_{i}$ and by $R_{s}$ the possibilistic reliability of the system. In case of possibilistic independence we can say that the possibilistic reliability of the system may be given as;

$$
R_{s}=\tilde{\phi}\left(r_{1}, r_{2}, r_{3}, r_{4}, r_{5}\right)
$$

and the possibilistic fuzzy reliability can be obtained by fuzzifying either by the above equations

$$
\begin{aligned}
R_{s} & =\left(r_{1} \tilde{\wedge} r_{4}\right) \tilde{\vee}\left(r_{2} \tilde{\wedge} r_{5}\right) \tilde{\vee}\left(\tilde{r}_{1} \wedge \tilde{r}_{3} \wedge \tilde{r}_{5}\right) \vee\left(\tilde{r}_{2} \wedge \tilde{r}_{3} \wedge \tilde{r}_{4}\right) \\
& =\left(r_{1} \tilde{\vee} r_{2}\right) \tilde{\wedge}\left(r_{4} \tilde{\vee} r_{5}\right) \tilde{\wedge}\left(r_{1} \tilde{\vee} r_{5} \tilde{\vee} r_{3}\right) \tilde{\wedge}\left(r_{2} \tilde{\vee} r_{4} \tilde{\vee} r_{3}\right)
\end{aligned}
$$


For numerical computation, we consider the following trapezoidal fuzzy numbers based on hypothetically selected values:

The possibilistic reliability of the all components in trapezoidal form is given as follows.

\begin{tabular}{|c|l|}
\hline Components $(i)$ & Possibilitic reliability of each component, $i$ \\
\hline$C_{1}$ & $(.045, .054, .055, .066)$ \\
\hline$C_{2}$ & $(.038, .032, .043, .048)$ \\
\hline$C_{3}$ & $(.042, .052, .053, .063)$ \\
\hline$C_{4}$ & $(.046, .056, .057, .069)$ \\
\hline$C_{5}$ & $(.046, .055, .056, .068)$ \\
\hline
\end{tabular}

Now applying the methodology described in the equation (18) and (19) the posfust reliability of the system can be calculated as;

$$
\mathrm{R}_{\mathrm{S}}=(.043, .052, .058, .064)
$$

\section{CONCLUSION}

This present paper has attempted to investigate the system reliability in the context of fuzzy set theory and possibility theory. We have discussed the fuzzy reliability of network i.e. series, parallel, k-out of - n, bridge and non- series parallel network. In the latter, the initial input reliability is modeled as fuzzy set on the universe of probability values. This allows us to model situations in which the single probability is supplied in place of a range of values. Expressions for the fuzzy reliabilities of series, parallel and k-out of $\mathrm{n}$ configuration networks have been obtained using fuzzy numbers as well as extension principle. These expressions are given in equations (4) to (8). Bridge network has also been studied. Its profust reliability expression, that is, equation (11), has been obtained using fuzzy probabilities. Bridge network has also been discussed for obtaining its profust reliability estimates. For this purpose concept of structure function, minimal path and minimal cuts have been used. The expression for posfust reliability is given in equations (19). Numerical computations for profust and posfust reliabilities have also been performed to examplify the process. Results of profust and posfust reliability estimates are given in (15) and (20) respectively.

\section{REFERENCES}

1. Liu Bi-Feng, Zhang Jian-Feng, Lu Ying-Tang, "Predicting and evaluating separation quality of micellar electrokinetic capillary chromatography by artificial neural networks", Electrophoresis Vol.23 (2002); pp. 1279-1284. 
2. M. Oussalah and M. Newby, "Analysis of serial-parallel systems in the framework of Fuzzy/possibility approach." Reliability Engineering and system safety. Vol. 79 (2003); pp. 353-368.

3. Mawanda Mbila-Mambua, Temba Shonhiwab, "The minimal mathematical structure for a synchronic approach to fuzzy set theory", Fuzzy Sets and Systems 151 (2005); pp. 491-501.

4. Zadeh L.A., "Fuzzy sets as a basis for a theory of possibility." Fuzzy Sets and Systems, 1 (1978); pp. 3-28.

5. Zadeh L.A., "Probability theory and fuzzy logic are complementary rather than Competitive.” Technometrices. 37 (3) (1995); pp. 271-279.

6. Zadeh L.A., "Fuzzy logic.” IEEE Transactions on Computer, (21) (1988); pp:83-93.

7. Cai K.Y. and Wen C.Y., "Fuzzy variables as a basis for a theory of fuzzy reliability in the possibility context" in Fuzzy sets and systems, 42, (1991a); pp. 145-172.

8. Jen - Shyan, W.; Rong - Jaye, C.: "Efficient Algorithm for Reliability of a Circular Consecutive k-out-of-n: F System”, IEEE TR on Reliability, Vol. 55, issue - 1, pp 163-164, 2006.

9. M.K. Sharma and D. pandey, Fuzzy Reliability and Fuzzy Availability of a Three Unit Degradable System, International J. of Math. Sci. \& Engg. Appls. (IJMESA), ISSN 0973-9424, Vol.3 No. II (2009), pp.199-213. 
